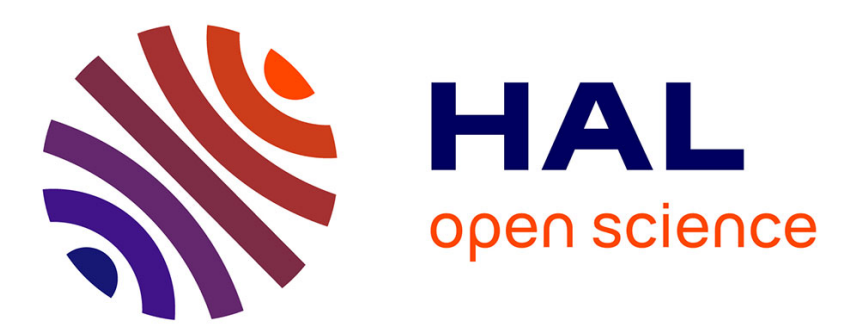

\title{
DFT-assisted solid-state NMR characterization of defects in Li2MnO3
}

Jon Serrano-Sevillano, Dany Carlier, Amaia Saracibar, Juan Miguel Lopez del Amo, Montse Casas-Cabanas

\section{> To cite this version:}

Jon Serrano-Sevillano, Dany Carlier, Amaia Saracibar, Juan Miguel Lopez del Amo, Montse CasasCabanas. DFT-assisted solid-state NMR characterization of defects in Li2MnO3. Inorganic Chemistry, 2019, 58 (13), pp.8347-8356. 10.1021/acs.inorgchem.9b00394 . hal-02171093

\section{HAL Id: hal-02171093 https://hal.science/hal-02171093}

Submitted on 2 Jul 2019

HAL is a multi-disciplinary open access archive for the deposit and dissemination of scientific research documents, whether they are published or not. The documents may come from teaching and research institutions in France or abroad, or from public or private research centers.
L'archive ouverte pluridisciplinaire HAL, est destinée au dépôt et à la diffusion de documents scientifiques de niveau recherche, publiés ou non, émanant des établissements d'enseignement et de recherche français ou étrangers, des laboratoires publics ou privés. 


\title{
DFT-assisted solid state NMR
}

\section{characterization of defects in $\mathrm{Li}_{2} \mathrm{MnO}_{3}$}

\author{
Jon Serrano-Sevillano, ${ }^{\dagger, \ddagger}$ Dany Carlier, ${ }^{\top}$ Amaia Saracibar, ${ }^{\ddagger}$ Juan Miguel Lopez del \\ Amo, ${ }^{*, \dagger}$ and Montse Casas-Cabanas ${ }^{*, \dagger}$ \\ $\dagger$ †IC energiGUNE, Parque Tecnológico de Álava, C/Albert Einstein 48, 01510 Miñano, \\ Álava, Spain \\ $\ddagger$ Physical Chemistry Department, Basque Country University, Pharmacy Faculty, \\ Vitoria-Gasteiz, Álava, Spain \\ ๆCNRS, Université Bordeaux, Bordeaux INP, ICMCB UMR5026, F-33600 Pessac, France \\ E-mail: jmlopez@cicenergigune.com; mcasas@cicenergigune.com \\ Phone: +34 945297108
}

\begin{abstract}
The complete description of defective structures and their impact on materials behavior is a great challenge due to difficulties associated with their reliable characterization in the nanoscale. In this paper density functional theory (DFT) calculations are used to elucidate the solid state nuclear magnetic resonance (NMR) spectra of $\mathrm{Li}_{2} \mathrm{MnO}_{3}$ which, combined with X-ray diffraction (XRD), provide a full description of disorder in this compound. While XRD allows accurate quantification of planar defects, the use of solid state NMR reveals limited vacancy concentrations that were undetected by XRD as NMR is highly sensitive to the atomic local environments. The combination of these methods is here proven to be highly effective in overcoming the challenges of describing in great detail limited concentrations of disorder in transition metal oxides, providing information about structural variables that are essential to their application.
\end{abstract}




\section{Introduction}

In many functional materials defects form complex structures whose reliable description is of extreme relevance to understand their effect on material's properties. Correlating defects and defect interactions with function remains however a great challenge and requires a combined approach. Solid state nuclear magnetic resonance (NMR) is a very useful technique for the evaluation and quantification of the structural features of a material at a local level and offers a very interesting perspective for the full structural description of a material in combination with the global picture provided by X-ray diffraction (XRD). ${ }^{1-5}$ In particular, solid state NMR of paramagnetic cathode materials is very sensitive to local discontinuities as the magnetic interactions governing the NMR spectra of these materials are strongly affected by even very minor changes in the bond distances and angles linking the atoms. ${ }^{4-7}$

The accurate description and quantification of defects in polycrystalline materials such as transition metal oxides provides very valuable information, as proper understanding of the underlying thermodynamics and kinetics of functional materials unavoidably requires the framework of both structure and microstructure. This is particularly the case of Li-rich cathode materials $\left(\mathrm{xLi}_{2} \mathrm{MnO}_{3} \cdot(1-\mathrm{x}) \mathrm{LiMO}_{2}\right.$ or $\mathrm{Li}_{1+\mathrm{x}} \mathrm{M}_{1-\mathrm{x}} \mathrm{O}_{2}$, where $\mathrm{M}$ is typically $\left.\mathrm{Mn}, \mathrm{Ni}, \mathrm{Co}\right)$, which represent a transformational approach for creating advanced energy materials as they combine the beneficial effects of standard cationic redox activity with new reversible anionic redox processes, resulting in remarkable capacities. ${ }^{8-11}$ However, these materials are known to suffer from fast voltage and capacity fading as a consequence of a major structural reorganization occurring upon cycling that is still the object of intense research. ${ }^{12-19}$ Significant efforts have been taken in recent years to understand and overcome these issues to foster their commercial implementation (including synthetic methods, ${ }^{20-23}$ chemical modifications through the use of dopants ${ }^{24-33}$ and surface modification, ${ }^{12,20,34-37}$ among others). Still, full understanding of their complex functional behavior is hindered by their microstructural complexity mainly because Li-rich oxides unavoidably crystallize with significant amounts of stacking faults. ${ }^{38-43} \mathrm{Li}_{2} \mathrm{MnO}_{3}$, the end member of this family of materials, represents an 
excellent model material for understanding the microstructural complexity of this family. $\mathrm{Li}_{2} \mathrm{MnO}_{3}$ is known to crystallize in a $C 2 / m$ unit cell with alternation of layers with pure $\mathrm{Li}$ and $\mathrm{Li} / \mathrm{Mn}$ atoms exhibiting a honeycomb like ordering (see Figure 1 (a)). The ideal structure of this compound exhibits three different lithium atomic positions; two of them located in the lithium layers (Wyckoff positions $2 c$ and $4 h$ ) and one corresponding to the lithium in the transition metal layer (Wyckoff position 2b), as shown in the local environments represented in Figure 1 (b-d) respectively.

\section{(a)}
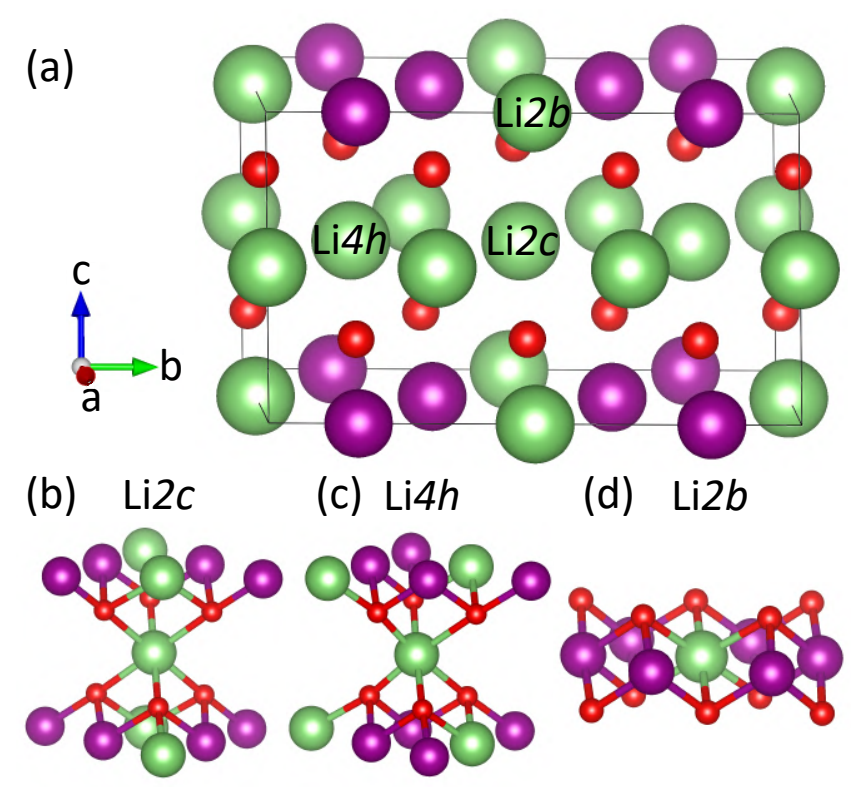

Figure 1: (a) Structure of $\mathrm{Li}_{2} \mathrm{MnO}_{3}$ where the different crystallographic sites of lithium are shown. (b-d) Local environment of each crystallographically different lithium site.

As in all Li-rich materials, stacking faults resulting from planar shifts of the mixed Li/Mn layer are energetically favorable although their extent strongly depends on the synthesis conditions (precursors, temperature and time). ${ }^{38,39,42,43}$ These stacking faults can be detected by different characterization techniques such as XRD ${ }^{42,43}$ transmission electron microscopy (TEM) ${ }^{39,40}$ or solid state NMR, ${ }^{44,45}$ although their quantification has generally represented a challenging task. Bréger et al. used $\mathrm{DiFFaX}^{46}$ simulations to model XRD data to qualitatively analyze stacking faults frequency in $\mathrm{Li}_{2} \mathrm{MnO}_{3} \cdot{ }^{44}$ They also showed that defects strongly modify its NMR spectrum, although additional resonances were not assigned. In a more re- 
cent work, the assignment of extra ${ }^{17} \mathrm{O}$ solid state NMR resonances was done by Seymour et al. and the percentage of stacking faults was estimated from the ratio of intensities. ${ }^{45}$ The acquisition and analysis of ${ }^{17} \mathrm{O}$ solid state NMR spectra is however challenging due to the low natural abundance of ${ }^{17} \mathrm{O}$ and due to the fact that the active center is usually directly bonded to the oxygen, causing signal broadening and large shifts.

The quantitative determination of stacking faults from powder diffraction data is now pos-

sible with the FAULTS software, ${ }^{47-49}$ which enables the refinement of experimental diffraction patterns. This approach has been successfully applied to several materials, including $\mathrm{Li}_{2} \mathrm{MnO}_{3} \cdot{ }^{42,50-53}$ The quantitative results obtained in a previous combined XRD and TEM study of $\mathrm{Li}_{2} \mathrm{MnO}_{3}$ samples exhibiting microstructural variability represent an excellent opportunity to endeavor the analysis and assignment of the ${ }^{6} \mathrm{Li}$ solid state NMR spectra of defective $\mathrm{Li}_{2} \mathrm{MnO}_{3}$. Assisted by first-principles calculations, we provide here an explanation to how local environments alterations change the Fermi contact shift allowing the assignment of the different signals in the NMR spectra, correlating NMR shifts to microstructural features. The combination of the results obtained from different techniques allows achieving an accurate description of defects in Li-rich oxides, represent an excellent case study to discuss the suitability of each technique for their study and provide new pathways to understand the correlation between disorder and function.

\section{Results and discussion}

\section{Experimental XRD patterns and NMR spectra}

Three different $\mathrm{Li}_{2} \mathrm{MnO}_{3}$ samples (A, B and C) have been synthesized and their XRD patterns are shown in Figure 2 (a). The inset of the figure shows a zoom of the XRD patterns in the $2 \theta_{C u}$ range of $20-35^{\circ}$ where superstructure reflections arising from Li/Mn order manifest. Defect-free materials exhibit 5 superstructure peaks in this $2 \theta_{C u}$ range, while heavily faulted samples exhibit a single peak with a strongly asymmetric broadening commonly known as 
Warren fall. ${ }^{54}$ As expected from the synthesis conditions selected, the samples exhibit notable differences owing to their different microstructure. Sample A exhibits a negligible degree of stacking faults and therefore this sample is considered to be stacking faults free. According to the FAULTS refinement performed in a previous work, ${ }^{42}$ sample B contains a low amount of stacking faults (13\%) and sample C a high amount (42\%).

Figure 2 (b) shows the ${ }^{6} \mathrm{Li}$ solid state NMR spectra of samples A-C in the region of interest (the full spectra, from 4000 to -2000 ppm, are shown in Figure S1). The dominant interactions in the ${ }^{6} \mathrm{Li}$ solid state NMR spectra of paramagnetic $\mathrm{Li}_{2} \mathrm{MnO}_{3}$ are the Fermi contact shifts generated by the unpaired electron density transferred from the paramagnetic manganese metals into the ${ }^{6} \mathrm{Li}$ spins through hybridization of the Li-O-Mn bond. The size of this interaction is a function of the unpaired electron spin density transferred to the nucleus and this property is considered to be additive. ${ }^{55-59}$ The final Fermi interaction or paramagnetic shift observed in the NMR spectrum can be therefore theoretically estimated considering all the individual interactions, where the sign of the transfer can be positive or negative. ${ }^{55}$ In a fully coordinated $\mathrm{MnO}_{6}$ octahedron Li-O-Mn bonds at $90^{\circ}$ have a positive net spin density transfer of 120-150 ppm, while the bonds at $180^{\circ}$ induce a negative spin polarization of $60-125 \mathrm{ppm} .{ }^{56}$ Figure $1(\mathrm{~b}, \mathrm{c})$ shows that there are eight manganese atoms in the first coordination sphere of $\mathrm{Li} 2 c$ and $\mathrm{Li}\left\{h\right.$. Four of them are double bonded via a $90^{\circ} \mathrm{Li}$ O-Mn angle and the other four are single bonded via a $180^{\circ} \mathrm{Li}-\mathrm{O}-\mathrm{Mn}$ angle. Assuming the additive nature of the Fermi contact interaction, the NMR signals of the lithium atoms in the lithium layer $(\operatorname{Li} 2 c$ and $\operatorname{Li}\{h)$ are expected to appear at around $750 \mathrm{ppm}$. On the other hand, as shown in Figure 1 (d), Li2b is surrounded by six manganese atoms, which are linked by a double $90^{\circ} \mathrm{Li}-\mathrm{O}-\mathrm{Mn}$ bond. The Li $2 b$ signal is therefore expected at around 1500 ppm in the NMR spectrum. In agreement with this, previous ${ }^{6} \mathrm{Li}$ and ${ }^{7} \mathrm{Li}$ NMR studies of $\mathrm{Li}_{2} \mathrm{MnO}_{3}$ assigned the two resonances at around $750 \mathrm{ppm}$ to $\mathrm{Li} 2 c$ and $\mathrm{Li} 4 h$ and the third one at $1600-1800 \mathrm{ppm}$ to Li2b positions. ${ }^{6,44,55,60-63}$

From the close inspection of the experimental ${ }^{6} \mathrm{Li}$ NMR spectra shown in Figure 2 (b) we 


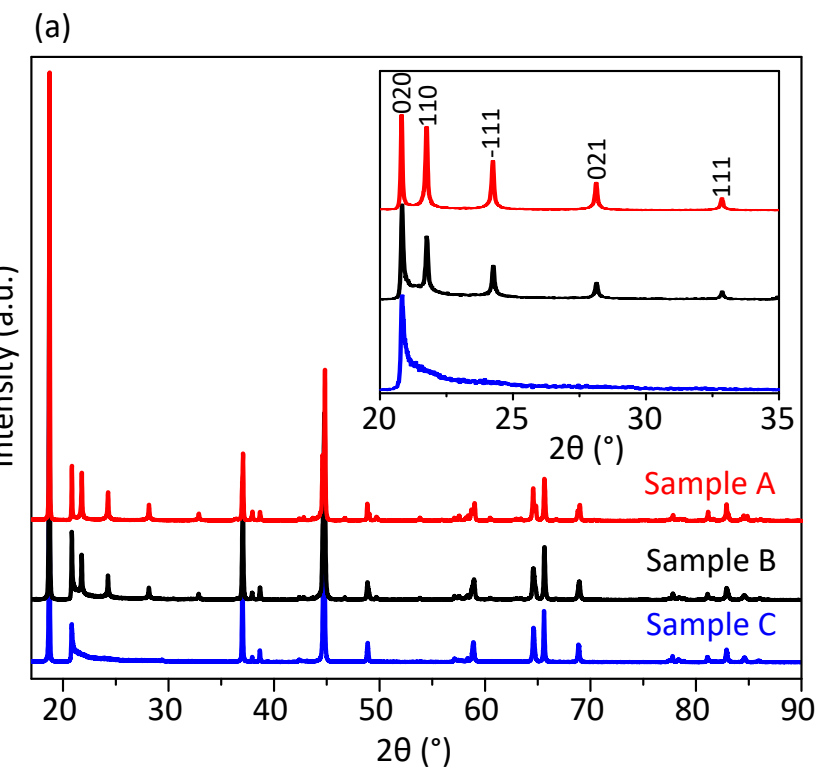

(b)

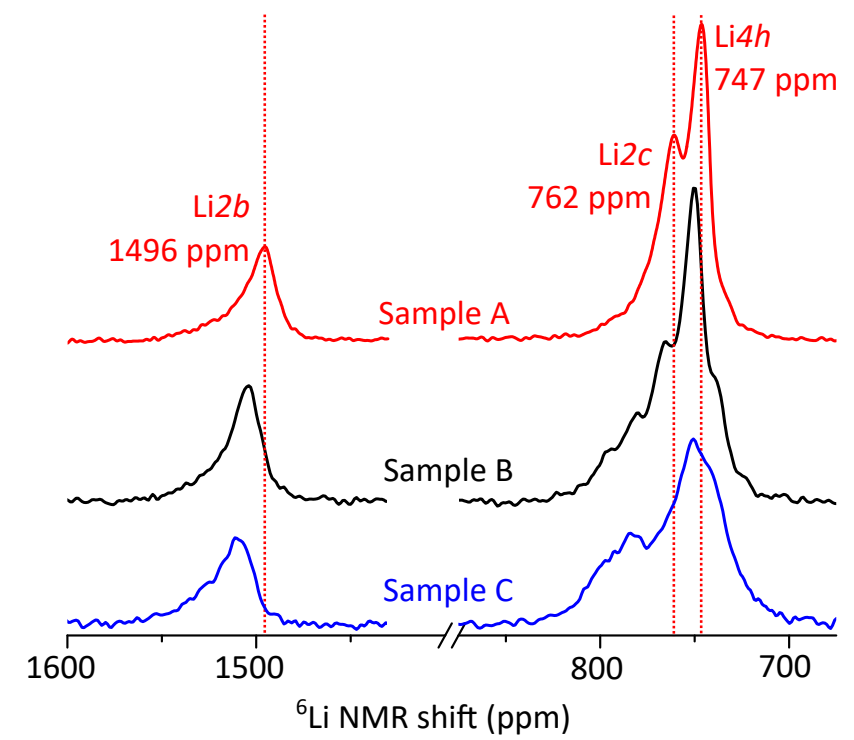

Figure 2: (a) XRD pattern of samples A, B and C $\left(\lambda_{C u}=1.54056 \AA\right)$. Superstructure peaks from the XRD pattern of the samples are shown as inset. (b) ${ }^{6} \mathrm{Li}$ solid state MAS-NMR spectra of samples $\mathrm{A}$ to $\mathrm{C}$ recorded at $50 \mathrm{kHz}$. Spectra are normalized with the area of the set of peaks at $750 \mathrm{ppm}$. The dashed red line shows the position for the experimental peaks from sample A.

observe that sample A indeed exhibits two main resonances at around $750 \mathrm{ppm}$ related to Li2c and Li $4 h$, while samples B and C, on the contrary, exhibit a higher number of overlapped signals in this region. These additional resonances are ascribed to the new lithium sites generated by stacking faults as previously reported by Bréger et al. ${ }^{44}$ In turn, while a single 
resonance is expected at around $1500 \mathrm{ppm}$ for lithium ions in Li2b positions, all three samples exhibit an asymmetric shape due to the presence of overlapped signals at higher ppm values.

In general, NMR experiments can be regarded as quantitative being the integral intensity under a particular signal directly proportional to its population in the sample. Nevertheless, in certain cases, quantification by solid state NMR might not be straightforward (but still possible). ${ }^{64}$ This is for example the case for paramagnetic materials due to their large spectral window and broad resonances where pulse imperfections or distinct magic angle spinning (MAS) rotational sideband patterns should be carefully considered. ${ }^{65}$ In addition, the extremely rapid longitudinal and transversal relaxation of the nuclear spins due to paramagnetic interactions could lead to undetectable resonances. However, the evaluation of similar ${ }^{6} \mathrm{Li}$ NMR signals ascribed to analogous lithium environments is feasible as in these cases the effects previously mentioned are approximately constant. The ratio between the clusters of signals at around $750 \mathrm{ppm}$ and $1500 \mathrm{ppm}$ corresponds to the percentage of lithium in lithium layers vs. lithium in manganese layers, and the ideal value should be 3 (two Li $4 h$ and one $\operatorname{Li} 2 c$ against $\mathrm{Li} 2 b)$. In our samples, the calculated ratios for samples $\mathrm{B}$ and $\mathrm{C}$ are similar (3.12 and 3.13 respectively) while it is larger for sample A (3.26), which suggests that sample A has a lower content of lithium ions in Li2b position with respect to samples B and $\mathrm{C}$. The long reaction time and the higher temperature used in the synthesis of sample A could entail some lithium evaporation which would not be detected from XRD analysis due to the weak scattering factor of lithium nor using other analytical techniques such as induced coupled plasma (ICP), as minor stoichiometry differences are under the detection limit.

Figure 3 (a-c) shows the deconvolution for samples A-C respectively. The fitted shift positions and relative populations are listed in Table S1. The NMR signal of sample A observed at $1500 \mathrm{ppm}$ requires at least three resonances. In turn, the signals observed at $750 \mathrm{ppm}$ can be described using two peaks. The intensity ratio of these two resonances is opposite to the theoretical relative population of $\mathrm{Li} 2 c$ and Li $4 h$. However, the ratio between 
peaks 3 and 4 in samples B and C (which, as discussed below, are related to ideal Li2c and Li4h respectively) is close to the expected 1:2. This is indicative that the two resonances in sample A are the result of other overlapped signals with similar local environments.

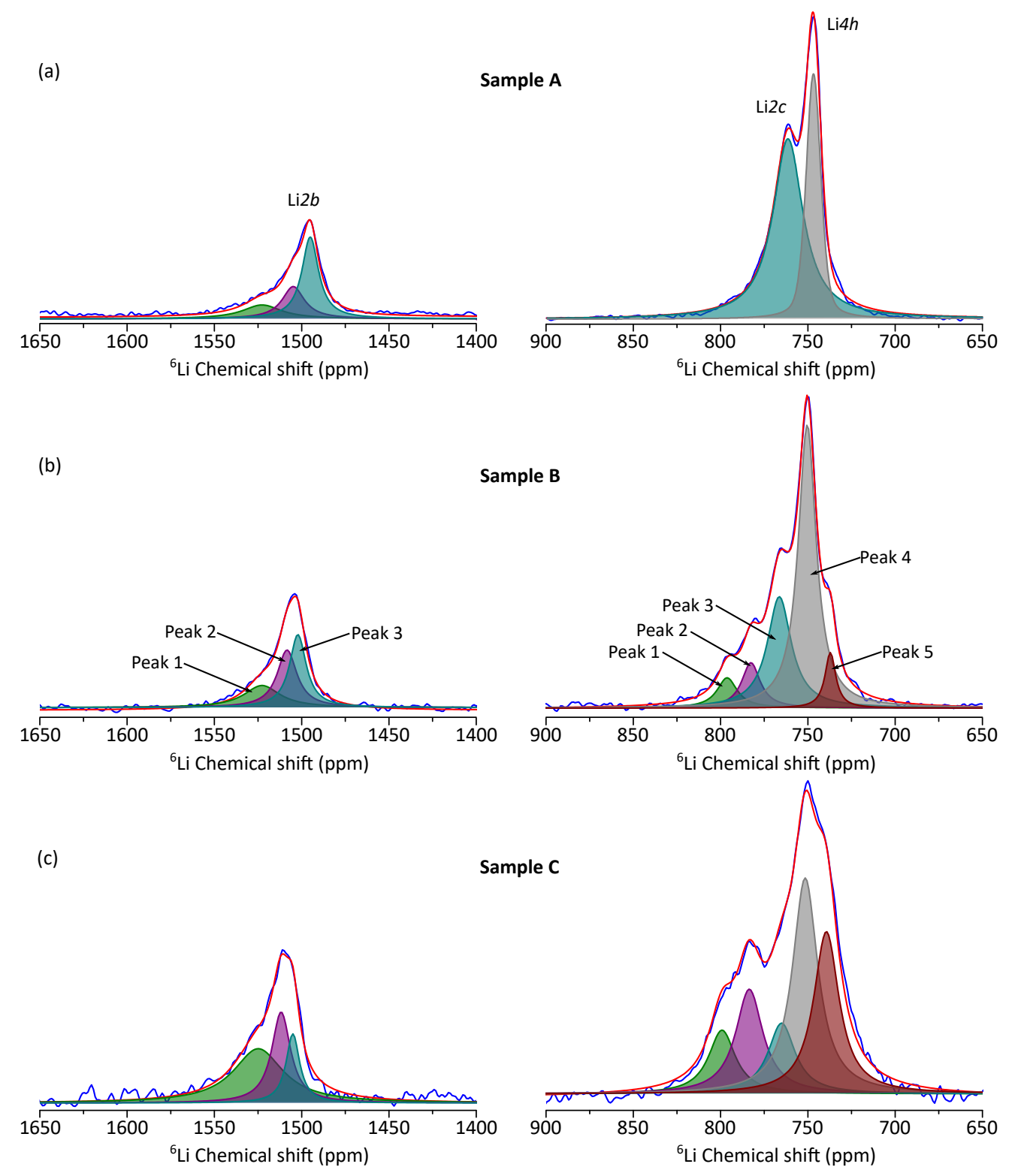

Figure 3: ${ }^{6} \mathrm{Li}$ solid state MAS-NMR spectra deconvolution of samples A-C respectively (ac). Blue curves correspond to the experimental spectra while red curves correspond to the calculated one. See experimental section and supplementary information for deconvolution details.

Similarly, samples B and C could neither be properly described using the ideal number of resonances, and the peaks centered at $1500 \mathrm{ppm}$ were also deconvoluted considering three 
different components. The signals centered at $750 \mathrm{ppm}$ required at least five peaks for a proper deconvolution, as shown in Figure $3(\mathrm{~b}, \mathrm{c})$. In this case, the extra peaks can be attributed to stacking faults. This is further confirmed by the fact that the positions of the shifts are similar for both samples. The relative intensities of peaks 3 and 4 become smaller as the degree of stacking faults increases, while signals 1,2 and 5 grow. Therefore we assign peaks 3 and 4 to the ideal stacking environments and resonances 1,2 and 5 to the new $\mathrm{Li}$ environments generated by the stacking faults.

\section{Simulated effect of stacking faults in the ${ }^{6} \mathrm{Li}$ NMR spectra}

The use of DFT calculations is generally crucial for the assignment of subtle local environment changes like defects on NMR shifts. Computed Fermi contact shifts of ideal and structures with stacking faults are here examined to get further insight into the nature of the shifts originated by defects in the NMR spectra of Figure 2 (b). Three different structures have been built and are shown in Figure 4 together with their computed ${ }^{6} \mathrm{Li}$ NMR shifts.

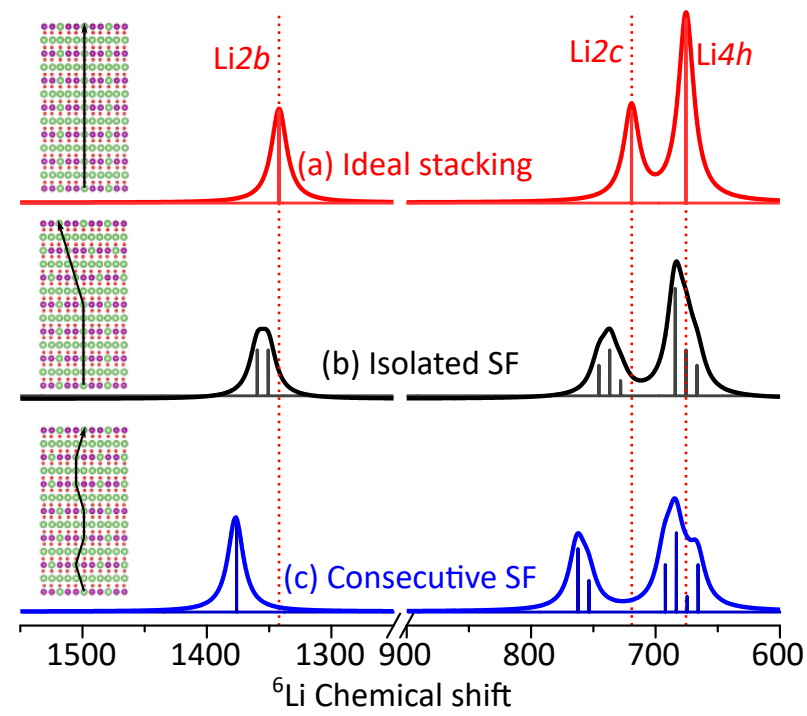

Figure 4: ${ }^{6} \mathrm{Li}$ NMR spectra simulation of (a) ideal, (b) structure with isolated stacking fault and (c) structure with consecutive stacking faults. The dashed red lines show the position for the simulated ideal peaks for $\operatorname{Li} 2 b, \operatorname{Li} 2 c$ and $\operatorname{Li} 4 h$. The insets show a reconstruction of the simulated structures with additional atoms in the $a b$ plane for a better observation of stacking faults. 
In order to use the same cell size in all three cases, a 6-fold along the $c$ axis supercell of the primitive unit cell has been generated with pymatgen. ${ }^{66}$ These correspond to (a) an ideal structure with no stacking faults, (b) a structure with a single isolated stacking fault corresponding to a consecutive displacement of $(1 / 3,-1 / 3,0)$ of all the layers above the stacking fault and (c) a highly faulted structure with several alternate layer displacements of $(1 / 3,-1 / 3,0)$ or $(-1 / 3,1 / 3,0)$. The ideal structure (Figure 4 (a)) exhibits, as expected, three signals in agreement with the assignments of Figure 3 and previous reports, ${ }^{6,44,55,60-63}$ while the presence of stacking faults in $\mathrm{Li}_{2} \mathrm{MnO}_{3}$ splits the three main resonances of the ideal structure into additional signals (Figure $4(\mathrm{~b}, \mathrm{c})$ ). The average calculated shifts of the simulated structures are shown in Table 1, together with average experimental peak positions for comparison. In the simulated structures, the signals of $\operatorname{Li} 2 b$ and $\operatorname{Li} 2 c$ of the defective structures are gradually displaced to higher ppm values with increasing amounts of stacking faults. On the contrary, Li $\{h$ exhibits additional signals at both lower and higher shifts, resulting in an average position that remains almost unmodified. These results agree well with the experimental patterns shown in Table 1 and in Figure 3, where the same trend is found.

Table 1: Computed and experimental average ${ }^{6} \mathrm{Li}$ NMR shifts. The latter correspond to the deconvolution using one peak per signal. The values in parenthesis correspond to the difference with respect to the ideal signal (for the case of the simulated shifts) or to sample A (for samples B and C).

\begin{tabular}{llll}
\hline Computed & $\mathrm{Li} 2 b(\mathrm{ppm})$ & $\mathrm{Li} 2 c(\mathrm{ppm})$ & $\mathrm{Li}\{h(\mathrm{ppm})$ \\
\hline Ideal & 1342 & 719 & 675 \\
Isolated SF & $1355(+13)$ & $738(+19)$ & $679(+4)$ \\
Consecutive SF & $1377(+35)$ & $760(+41)$ & $681(+6)$ \\
\hline Experimental & $\mathrm{Li} 2 b(\mathrm{ppm})$ & $\mathrm{Li} 2 c(\mathrm{ppm})$ & $\mathrm{Li} 4 h(\mathrm{ppm})$ \\
\hline $\mathrm{A}$ & 1499 & 762 & 747 \\
$\mathrm{~B}$ & $1506(+7)$ & $772(+10)$ & $750(+3)$ \\
$\mathrm{C}$ & $1511(+12)$ & $787(+25)$ & $747(+0)$ \\
\hline
\end{tabular}




\section{Simulated effect of vacancies and substitutions in the ${ }^{6} \mathrm{Li}$ NMR spec-}

\section{tra}

The combination of FAULTS refined XRD, NMR and DFT techniques has allowed assigning to relate the extra peaks shown in the spectra of samples B and C in Figure 3 to new environments created by stacking faults. The extra peaks of sample A, however, cannot be explained with planar defects (absence of Warren fall in the XRD pattern). On one hand, the peak at $1500 \mathrm{ppm}$ shows at least three different environments. On the other hand, even if the peak at $750 \mathrm{ppm}$ of sample $\mathrm{A}$ is deconvoluted using two peaks, their intensity ratio is opposite to the ideal one for $\operatorname{Li} 2 c: \operatorname{Li}\{h(2: 1$ instead of 1:2) which suggests that additional overlapped peaks caused by other unknown structural defects should be considered. In the following section different microstructural defects are simulated to identify the origin of such extra peaks: i) $\mathrm{Li}^{+} / \mathrm{H}^{+}$exchange, ii) lithium vacancies, iii) oxygen vacancies and iv) $\mathrm{Li}_{2} \mathrm{O}$ vacancies.

$\mathrm{Li}^{+} / \mathrm{H}^{+}$exchange

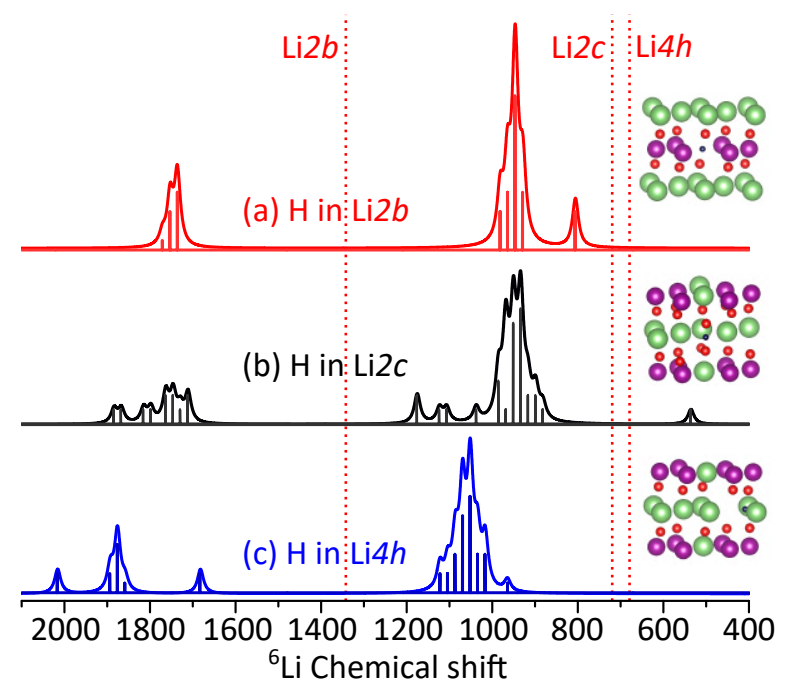

Figure 5: ${ }^{6} \mathrm{Li}$ NMR spectra simulation of $\mathrm{Li}_{1.96} \mathrm{H}_{0.04} \mathrm{MnO}_{3}$ with $\mathrm{Li}^{+} / \mathrm{H}^{+}$exchange in (a) $\mathrm{Li} 2 b$, (b) Li2c and (c) Li $4 h$ positions. The dashed red lines show the position for the ideal peaks. The insets show the local environment where the proton (the small black sphere) is present, not the whole computed structure. 
As previously mentioned sample A exhibits a lower content of lithium ions in Li $2 b$ position with respect to samples $\mathrm{B}$ and $\mathrm{C}$. A first scenario where the $\mathrm{Li}^{+}$are replaced by $\mathrm{H}^{+}$from moisture has been considered. $\mathrm{Li}^{+} / \mathrm{H}^{+}$exchange has been reported to occur in acidic medium as well as when electrochemically oxidized in non aqueous electrolyte. ${ }^{67-71}$ Figure 5 shows the computed NMR corresponding to a material with $\mathrm{Li}_{1.96} \mathrm{H}_{0.04} \mathrm{MnO}_{3}$ formula. Strikingly, less than $2 \%$ of hydrogen severely modifies the local environments which makes the NMR signals appear at much higher ppm than the one calculated for ideal $\mathrm{Li}_{2} \mathrm{MnO}_{3}$. We believe that such difference arises from the fact that in the calculated relaxed structure hydrogen atoms are displaced from the center of the octahedron. As a consequence, the density charge of the oxygen atoms is severely modified and this is spread further away. Although the possibility of having a lower amount of $\mathrm{Li}^{+} / \mathrm{H}^{+}$defects in the experimental spectrum is plausible, from the comparison of the NMR spectra in Figure 3 and the simulated one in Figure 5 we believe these defects are unlikely to exist in our material.

\section{Lithium vacancies}

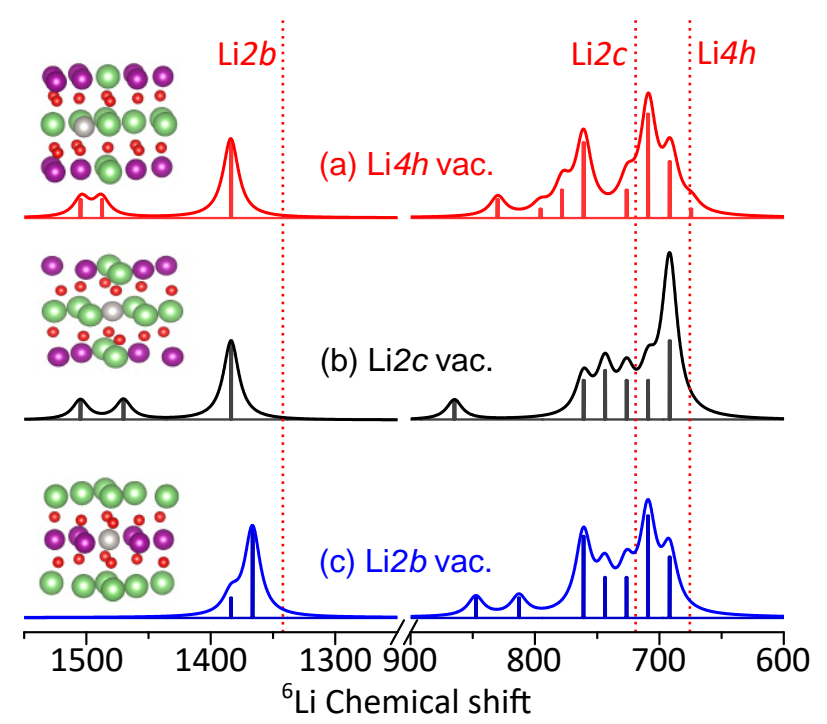

Figure 6: ${ }^{6} \mathrm{Li}$ NMR spectra simulation of $\mathrm{Li}_{1.96} \mathrm{MnO}_{3}$ with lithium vacancies on positions (a) Li4h, (b) Li2c and (c) Li2b. The dashed red lines show the positions for the ideal peaks. The insets show the local environment where the lithium vacancy (marked with a gray sphere) is present, not the whole computed structure. 
A second scenario to account for lithium deficiencies in sample A would be that the high synthesis temperatures generate lithium vacancies that are charge compensated via electron hole formation in oxygen atoms, as proposed to occur during the charge process. ${ }^{72-75}$

In order to evaluate the impact of how lithium vacancies modify in the NMR spectra a single isolated lithium atom is removed from the structure and its total energy is calculated. Lithium is removed from its three crystallographic positions (2b, $2 c$ and $4 h)$ and the calculated total energy is the same in all cases. Therefore, it can be concluded that any of these three lithium defect structures would be equally likely to occur. As seen in Figure 6 (a-c) lithium vacancies increase the NMR shifts for all the crystallographic lithium positions. Even if the presence of electron holes has only been proposed to occur after electrochemical oxidation, ${ }^{72,74}$ this kind of defect cannot be totally discarded in the pristine sample as they can overlap with the main signal.

\section{Oxygen vacancies}

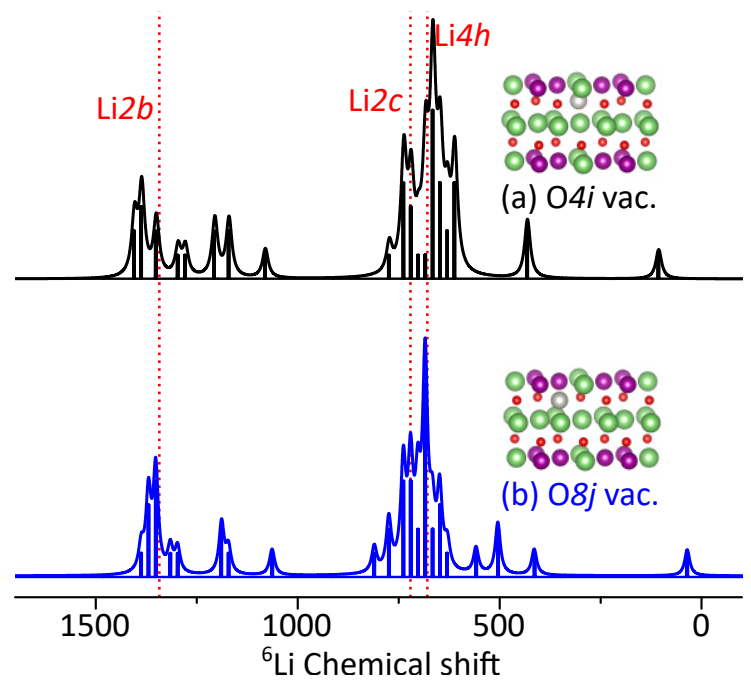

Figure 7: ${ }^{6} \mathrm{Li} \mathrm{NMR}$ spectra simulation of $\mathrm{Li}_{2} \mathrm{MnO}_{2.96}$ with oxygen vacancies on positions (a) $4 i$ and (b) $8 j$. The dashed red lines show the positions for the ideal peaks. The insets show the local environment where the oxygen vacancy (marked with a gray sphere) is present, not the whole computed structure.

Reductive atmospheres have been used by some groups to synthesize oxygen vacant 
structures. ${ }^{76,77}$ These generate $\mathrm{Mn}^{I I I}$ ions which improve the conductivity, enhancing chargetransfer ability and electrochemical performances. ${ }^{76-78}$ The experimental detection and quantification of such vacancies would be very interesting and useful to support these synthetic efforts. Oxygen vacancies in both $\mathrm{O}_{4} i$ and $\mathrm{O} 8 j$ positions were considered and the resultant spectra are shown in Figure 7. In both cases the average formula unit of the computed structure is $\mathrm{Li}_{2} \mathrm{MnO}_{2.96}$. Oxygen vacancies are found to severely modify the local environment changing the spin transfer mechanisms and thus, generating a large set of new peaks. In addition to the resonances close to ideal signals (shown with a dashed red line), some additional peaks appear in the range 1000-1250 ppm and 0-200 ppm. These peaks are not observed in our experimental NMR spectra (Figure 2 and Figure S1) and again, even if differences between the simulated defect concentration and the experimental one should be considered, the presence of oxygen vacancies in our material can be ruled out because the extra peaks would still be present. The absence of a reducing atmosphere in our synthesis of the material further supports this result.

\section{$\mathrm{Li}_{2} \mathrm{O}$ vacancies}

Finally, the combination of lithium and oxygen removal with the loss of $\mathrm{Li}_{2} \mathrm{O}$ has been considered. It is well established that $\mathrm{Li}_{2} \mathrm{O}$ removal upon electrochemical oxidation occurs. ${ }^{16,20,68,69,79-85}$ In agreement with previous reports ${ }^{86-88}$ we have found that the removal of $\mathrm{O} 8 \mathrm{j}$ is more energetically favored with an energy difference close to $20 \mathrm{meV}$ per formula unit, while lithium atoms close to the oxygen vacancy are the most energetically favored, especially those with a Li $4 h$-vac.-Li2 $6180^{\circ}$ configuration (see supplementary information and Figure S2). The NMR simulation corresponding to the most stable $\mathrm{Li}_{1.92} \mathrm{MnO}_{2.96}$ structure is shown in Figure 8. The removal of two lithium and one oxygen atoms generate a slight shift of Li2c and Li $4 h$ signals to higher ppm values, and a number of new signals around all ideal positions. The lower ppm shift of the two isolated peaks on the right part of the spectra are the consequence of lithium atoms with an oxygen vacancy in their octahedron. 


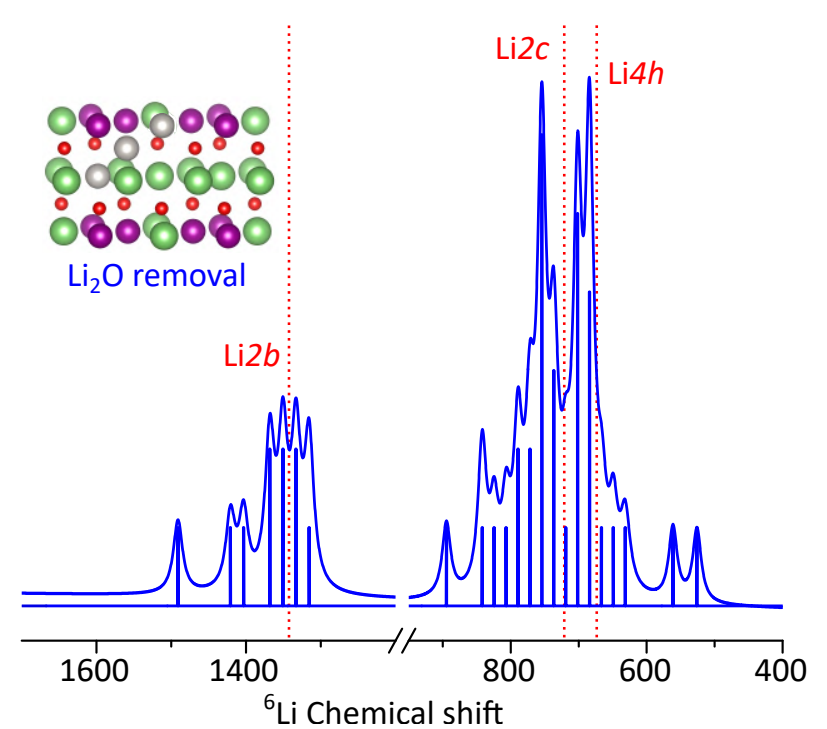

Figure 8: ${ }^{6} \mathrm{Li}$ NMR spectra simulation of $\mathrm{Li}_{1.92} \mathrm{MnO}_{2.96}$ with $\mathrm{Li} 4 h$, $\mathrm{Li} 2 b$ and $\mathrm{O} 8 j$ vacancies. The dashed red line shows the position for the ideal peaks. The inset shows the local environment where the $\mathrm{Li}_{2} \mathrm{O}$ vacancy (marked with gray spheres) is present, not the whole computed structure.

Consequently, the transferred spin density is smaller. Simulations including the ideal and new $\mathrm{Li} 2 b$ environments are able to reproduce the asymmetric lineshape found experimentally, except for the two peaks at 500-600 ppm. These could overlap with the main peak at $750 \mathrm{ppm}$ and that are the consequence of 5-coordinated lithium atoms whose transferred spin density is reduced with respect to ideal 6-coordinated lithium atoms.

\section{Discussion}

The ${ }^{6} \mathrm{Li}$ NMR spectra of three samples with varying degree of planar defects have been compared. Assisted by DFT calculations, it has been confirmed that while ideal $\mathrm{Li}_{2} \mathrm{MnO}_{3}$ exhibits three ${ }^{6} \mathrm{Li}$ NMR signals (one per each different lithium site), stacking faults generate a higher number of overlapped signals. As a consequence, a displacement to higher shifts of the signals of $\operatorname{Li} 2 b$ and $\operatorname{Li} 2 c$ is observed, while the average position for the signal of Li $4 h$ is maintained constant. This behavior is experimentally reproduced when comparing samples with low and high degree of stacking faults. 
Peaks 1 and 2 and 5 from the deconvolution of the peak at $750 \mathrm{ppm}$ in Figure 3 (b,c) are related to the new environments generated by the stacking faults. The sum of these new lithium environments can thus be used to quantify the degree of stacking faults as previously done by Seymour et al. using ${ }^{17} \mathrm{O}$ NMR data. ${ }^{45}$ In this work it is considered that stacking faults modify oxygen environments in the faulted layer and the adjacent ones, and therefore the number of modified environments should be three times the degree of stacking faults. Nevertheless, if stacking faults are consecutive, the number of modified environments will be lower, as the effects of consecutive defects will overlap. Note that the same ratio will be found for lithium environments. In this case, the number of modified lithium environments will range from 1 (for $100 \%$ consecutive stacking faults) to 3 (for 100\% isolated stacking faults) as seen in supplementary information and Figure S3.

Table 2: Degree of stacking faults (SF) obtained with FAULTS program from XRD data and number of modified lithium environments obtained from the NMR peak fitting.

\begin{tabular}{llll}
\hline Sample & SF (XRD) $(\%)^{42}$ & Mod. Li env. (NMR) (\%) & Ratio \\
\hline A & None & None & None \\
B & 13 & 21 & 1.6 \\
C & 42 & 57 & 1.4 \\
\hline
\end{tabular}

Table 2 shows the comparison of the degree of stacking faults obtained by XRD using the FAULTS software, ${ }^{42}$ the sum of the percentage of new lithium environments measured by NMR and their ratio. In our study it is found that in samples B and C stacking faults are not isolated, which is in accordance with previous TEM observations. ${ }^{42}$ It should be noted that in highly faulted samples the probabilities of finding isolated stacking faults is strongly reduced.

Besides, even if the sample without stacking faults can be deconvoluted using two resonances, their intensity distribution does not correspond to the expected one. It has been thus concluded that other types of defects must be present and a deeper study to elucidate the origin of such deviation has been performed. The effect of $\mathrm{Li}^{+} / \mathrm{H}^{+}$exchange and lithium, oxygen and $\mathrm{Li}_{2} \mathrm{O}$ vacancies in the NMR shifts have been simulated. On the one hand, DFT 
calculated spectra show that single oxygen vacancies and $\mathrm{Li}^{+} / \mathrm{H}^{+}$exchange generate shifts which are clearly not present in our samples. On the other hand, both lithium and $\operatorname{Li}_{2} \mathrm{O}$ vacancies result in new environments and shifts to higher ppms that could be in agreement with our experimental data. However, the shifts obtained for lithium vacancies appear more isolated, which is why we believe that overall $\mathrm{Li}_{2} \mathrm{O}$ vacancies better reproduce the experimental spectrum of sample A. The strong overlapping of the different NMR signals coupled to the low amount of these defects (as they were not detected by XRD) hinders their quantification. The dominant effect of stacking faults in the spectra of samples $\mathrm{B}$ and $\mathrm{C}$ neither allows assessing the presence of $\mathrm{Li}_{2} \mathrm{O}$ vacancies in their structure, although a lesser extent is expected (if any) from the different synthesis conditions used to prepare these samples.

These results illustrate that the quantification of stacking faults from NMR data is only possible in samples where stacking faults appear as isolated defects, which is not the case here. However, the combination of XRD and NMR results can be used to estimate the trend of stacking faults to locally concentrate. Finally, while XRD can give us quantitative information about the degree of stacking faults, NMR is highly sensitive to other defects that are undetected by other techniques such as XRD or ICP. The decoupling of different types of defects and their quantification by ${ }^{6} \mathrm{Li}$ NMR however remains a challenge.

\section{Conclusions}

In this work the NMR spectra of three different $\mathrm{Li}_{2} \mathrm{MnO}_{3}$ samples have been elucidated with the help of DFT and XRD data. Samples prepared at $900{ }^{\circ} \mathrm{C}$ were found to mainly exhibit stacking faults resulting in additional peaks in their NMR spectra. DFT calculations have accurately reproduced the peak assignment of the ideal structure and structures with stacking faults. Their quantification by ${ }^{6} \mathrm{Li} \mathrm{NMR}$ is only possible if these are isolated, however, the comparison of the number of modified environments with XRD results can be used to characterize their trend to locally concentrate. From XRD data it was concluded 
that the sample prepared at $1000{ }^{\circ} \mathrm{C}$ was stacking faults-free, but a close inspection of its NMR spectrum suggested other structural defects instead. DFT calculations were used to discriminate between $\mathrm{Li}^{+} / \mathrm{H}^{+}$exchange and lithium, oxygen and $\mathrm{Li}_{2} \mathrm{O}$ vacancies, being the latter the scenario that could best reproduce the additional NMR features. While XRD gives accurate information about the degree of stacking faults, NMR is shown to be highly sensitive to other microstructural defects which are not easily detected with XRD. Both techniques are thus complementary and combined provide an accurate description of the microstructural complexities $\mathrm{Li}_{2} \mathrm{MnO}_{3}$ can exhibit. The combined XRD/NMR/DFT methodology described in this work is expected to be extremely useful for describing defect structures in a range of technologically relevant paramagnetic solids.

\section{Experimental section}

\section{Material synthesis.}

Mixtures of $\mathrm{Li}_{2} \mathrm{CO}_{3}$ and the $\mathrm{Mn}$ precursor $\left(\mathrm{MnO}\right.$ or $\left.\mathrm{MnCO}_{3}\right)$ were ball-milled for 5 minutes (SPEX SamplerPrep 8000 M Mixer/Mill) in a Li:Mn ratio 2.04:1. The lithium excess is to compensate its loss occurring during the heat treatment at high temperature. The mixture was then pelletized in a $1 \mathrm{~cm}$ diameter pellet with a pressure of 5 tones for 1 minute and submitted to a two-step heat treatment in air; the first one for 5 hours at $500{ }^{\circ} \mathrm{C}$ and the second one with varying time and temperature.In our previous work the choice of Mn precursors was shown to be key to control the amount of defects in $\mathrm{Li}_{2} \mathrm{MnO}_{3}$ samples prepared by solid state reactions. ${ }^{42}$ Here, we study two samples prepared under the same conditions of temperature and time $\left(900{ }^{\circ} \mathrm{C}\right.$ for 5 hours) but using two different precursors (sample B using $\mathrm{MnO}$ and sample $\mathrm{C}$ using $\mathrm{MnCO}_{3}$ ) plus a third sample (sample $\mathrm{A}$ ) that is prepared with $\mathrm{MnO}$ and calcined at $1000{ }^{\circ} \mathrm{C}$ for 72 hours are studied. The use of $\mathrm{MnCO}_{3}$ (sample $\mathrm{C}$ ) results in a sample with a large amount of stacking faults, while the use of MnO allows considerably reducing their amount (sample B) and even suppressing them using long annealing times 
and higher temperature (sample A).

\section{Sample characterization.}

All patterns were recorded on a Bruker D8 Discover instrument using monochromatic copper radiation $\left(\mathrm{Cu} \mathrm{K} \alpha_{1} \lambda=1.54056 \AA\right)$. Patterns were measured in a $2 \theta$ range of 15 $110^{\circ}$ with a step size of $0.01^{\circ}$ and a time per step of $1.550 \mathrm{~s}$. Representations and analyses of the crystal structures were done using the VESTA program. ${ }^{89-91}$

${ }^{6} \mathrm{Li}$ MAS solid state NMR experiments were performed on a Bruker 300WB spectrometer charged to a field of 4.69 T equipped with a $1.3 \mathrm{~mm}$ MAS probe. The samples were prepared in air. Spinning frequencies were set to $50 \mathrm{kHz}$ in all cases. A rotor synchronized spinecho pulse sequence $\left(90^{\circ}-\tau-180^{\circ} \tau_{1}\right.$ acquisition) was used with typical $90^{\circ}$ and $180^{\circ}$ pulses of 1.3 and $2.6 \mu \mathrm{s}$, respectively. A recycle delay of $0.5 \mathrm{~s}$ was used and around $165 \mathrm{k}$ scans were typically acquired in a ${ }^{6} \mathrm{Li} \mathrm{NMR}$ experiment. The spectra were referenced to a $1 \mathrm{M}$ solution of LiCl. The spectra were fitted using the Dmfit software. ${ }^{92}$ A summary of the fitting parameters can be found in Table S2. Magnetic measurements were done using a Quantum Design Physical Property Measurement System (PPMS) from 2.5-333 K.

\section{Computational details.}

The total energy and ${ }^{6} \mathrm{Li}$ NMR shifts for the different structures have been calculated using the Vienna Ab-initio Simulation Package (VASP). ${ }^{93,94}$ As in this work we aim to model diluted defects in a paramagnetic material, the use of the VASP code (plane waves and PAW potentials) is preferred to that of the more computer-demanding "all-electron" WIEN2k (FP-FLAPW) code, ${ }^{95}$ as it allows to consider large supercells. In a previous study the comparison of Fermi contact shifts computed by the two approaches in several polyanionic battery materials showed that for compounds with transition metal ions exhibiting only $\mathrm{t}_{2 g}$ electrons, the PAW method as implemented in VASP is as accurate as the FP-LAPW one. ${ }^{59}$ Spin-polarized DFT calculations were performed and projector augmented wave potentials ${ }^{94}$ were used to replace core electrons, whereas $\mathrm{Li}(2 \mathrm{~s}), \mathrm{Mn}(3 \mathrm{p}, 3 \mathrm{~d}, 4 \mathrm{~s})$ and $\mathrm{O}(2 \mathrm{~s}, 2 \mathrm{p})$ valence electrons were expanded in plane-waves with a cut off energy of $600 \mathrm{eV}$. The Perdew-Burke- 
Ernzerhof (PBE) ${ }^{96}$ exchange-correlation function was used together with a Monkhorst-Pack grid. While the unit cell was obtained from XRD, atomic positions were relaxed with a residual force threshold of $0.02 \mathrm{eV} \AA^{-1}$. The generalized gradient approximation with the Hubbard parameter correction $(\mathrm{GGA}+\mathrm{U})$ of Dudarev et al. ${ }^{97}$ was employed. As it is shown in the supplementary information (Figure S4), a U value of $3.9 \mathrm{eV}$ and the unit cell values obtained from the experimental refinement of XRD data of sample A $(a=4.927(3) \AA$, $b=8.523(3) \AA, c=5.024(2) \AA$ and $\left.\beta=109.39(3)^{\circ}\right)$ result in the best agreement with experimental ${ }^{6} \mathrm{Li}$ chemical shifts for $\mathrm{Li}_{2} \mathrm{MnO}_{3}$. A convergence of the total energy close to 0.5 $\mathrm{meV}$ per formula unit was achieved with these parameters. The atomic positions were allowed to vary while the unit cell size was maintained fixed. The total energy and NMR shifts of different $\mathrm{Li}_{2} \mathrm{MnO}_{3}$ stacking sequences were calculated using a representative amount of $\mathrm{k}$ points. Supercells were constructed with the experimental values, using pymatgen tool. ${ }^{66}$ The steps for the Fermi contact interaction calculation are shown in the supplementary information and Figure S5.

\section{Acknowledgement}

This work was supported by the Spanish Ministerio de Economía y Competitividad through ION-STORE grant (Proyectos I + D Retos 2016 program, project, reference number: ENE201681020-R). We acknowledge Santander Supercomputacion support group at the University of Cantabria who provided access to the supercomputer Altamira Supercomputer at the Institute of Physics of Cantabria (IFCA-CSIC), as well as Barcelona Supercomputer center, both members of the Spanish Supercomputing Network, for performing simulations/analyses. The authors acknowledge Maria Jaúregi from CIC energiGUNE for the assistance in PPMS data adquisition and Maider Saracibar for her help in the graphics design. 


\section{Supporting Information Available}

The following files are available free of charge.

- Full ${ }^{6} \mathrm{Li}$ solid state NMR spectra, deconvoluted experimental data, $\mathrm{Li}_{2} \mathrm{O}$ vacancy selection, comparison of stacking faults, choice of $U$ value and unit cell size, Fermi contact interaction calculation and technical NMR deconvolution fitting parameters.

\section{References}

(1) Pecher, O.; Mausolf, B.; Lamberts, K.; Oligschläger, D.; Niewieszol (née Merkens), C.; Englert, U.; Haarmann, F. The Solid Solution $\mathrm{Sr}_{1-x} \mathrm{Ba}_{x} \mathrm{Ga}_{2}$ : Substitutional Disorder and Chemical Bonding Visited by NMR Spectroscopy and Quantum Mechanical Calculations. Chem. - Eur. J. 2015, 21, 13971-13982.

(2) Haouas, M.; Taulelle, F.; Martineau, C. Recent advances in application of ${ }^{27} \mathrm{Al}$ NMR spectroscopy to materials science. Prog. Nucl. Magn. Reson. Spectrosc. 2016, 94-95, $11-36$.

(3) Youngman, R. NMR spectroscopy in glass science: A review of the elements. Materials 2018,11 .

(4) Pecher, O.; Carretero-Gonzalez, J.; Griffith, K. J.; Grey, C. P. Materials' methods: NMR in battery research. Chem. Mater. 2017, 29, 213-242.

(5) Magusin, P. C. M. M.; Seymour, I. D.; Pecher, O.; Grey, C. P. Modern Methods in Solid-state NMR: A Practitioner's Guide; R. Soc. Chem., 2018; pp 322-355.

(6) Grey, C. P.; Dupre, N. NMR Studies of Cathode Materials for Lithium-Ion Rechargeable Batteries. Chem. Rev. (Washington, DC, U. S.) 2004, 104, 4493-4512.

(7) Hodgkinson, P. Modern Methods in Solid-state NMR: A Practitioner's Guide; R. Soc. Chem., 2018; Vol. 15. 
(8) Armand, M.; Tarascon, J. M. Building better batteries. Nature 2008, 451, 652-657.

(9) Tarascon, J. M.; Armand, M. Issues and challenges facing rechargeable lithium batteries. Nature 2001, 414, 359-367.

(10) Xu, J.; Sun, M.; Qiao, R.; Renfrew, S. E.; Ma, L.; Wu, T.; Hwang, S.; Nordlund, D.; Su, D.; Amine, K.; Lu, J.; McCloskey, B. D.; Yang, W.; Tong, W. Elucidating anionic oxygen activity in lithium-rich layered oxides. Nat. Commun. 2018, 9, 1-10.

(11) Nayak, P. K.; Erickson, E. M.; Schipper, F.; Penki, T. R.; Munichandraiah, N.; Adelhelm, P.; Sclar, H.; Amalraj, F.; Markovsky, B.; Aurbach, D. Review on Challenges and Recent Advances in the Electrochemical Performance of High Capacity Li- and Mn-Rich Cathode Materials for Li-Ion Batteries. Adv. Energy Mater. 2018, 8, 1-16.

(12) Song, J. H.; Kapylou, A.; Choi, H. S.; Yu, B. Y.; Matulevich, E.; Kang, S. H. Suppression of irreversible capacity loss in Li-rich layered oxide by fluorine doping. J. Power Sources 2016, 313, 65-72.

(13) Ong, S. P.; Chevrier, V. L.; Hautier, G.; Jain, A.; Moore, C.; Kim, S.; Ma, X.; Ceder, G. Voltage, stability and diffusion barrier differences between sodium-ion and lithium-ion intercalation materials. Energy Environ. Sci. 2011, 4, 3680-3688.

(14) Okubo, M.; Yamada, A. Molecular Orbital Principles of Oxygen-Redox Battery Electrodes. ACS Appl. Mater. Interfaces 2017, 9, 36463-36472.

(15) McCalla, E.; Abakumov, A. M.; Saubanere, M.; Foix, D.; Berg, E. J.; Rousse, G.; Doublet, M.-L.; Gonbeau, D.; Novak, P.; Van Tendeloo, G.; Dominko, R.; Tarascon, J.M. Visualization of O-O peroxo-like dimers in high-capacity layered oxides for Li-ion batteries. Science 2015, 350, 1516-1521.

(16) Croy, J.; Kang, S.-H.; Balasubramanian, M.; Thackeray, M. $\mathrm{Li}_{2} \mathrm{MnO}_{3}$-based composite 
cathodes for lithium batteries: A novel synthesis approach and new structures. Electrochem. Commun. 2011, 13, 1063-1066.

(17) Wu, J. H.; Yang, L.; Liu, H. Synthesis and Electrochemical Properties of Spherical Nano-Structured and Nano-Agglomerated $\mathrm{Li}_{1.2} \mathrm{Mn}_{0.6} \mathrm{Ni}_{0.2} \mathrm{O}_{2}$ Cathode Materials for Lithium-Ion Batteries. Integr. Ferroelectr. 2015, 164, 52-59.

(18) Iddir, H.; Key, B.; Dogan, F.; Russell, J. T.; Long, B. R.; Bareño, J.; Croy, J. R.; Benedek, R. Pristine-state structure of lithium-ion-battery cathode material $\mathrm{Li}_{1.2} \mathrm{Mn}_{0.4} \mathrm{Co}_{0.4} \mathrm{O}_{2}$ derived from NMR bond pathway analysis. J. Mater. Chem. A 2015, 3, 11471-11477.

(19) Cheng, M.; Tang, W.; Sun, Y.; Zhu, K. Electrochemical properties of $\mathrm{Li}_{2} \mathrm{MnO}_{3}$ nanocrystals synthesized using a hydrothermal method. RSC Adv. 2015, 5, 7108871094 .

(20) Wu, Y.; Ming, J.; Zhuo, L.; Yu, Y.; Zhao, F. Simultaneous surface coating and chemical activation of the Li-rich solid solution lithium rechargeable cathode and its improved performance. Electrochim. Acta 2013, 113, 54-62.

(21) Zhang, Q.; Hu, X.; Zhan, D.; Peng, T. Pyrolysis of in situ formed lithium stearate: An effective strategy to activate $\mathrm{Li}_{2} \mathrm{MnO}_{3}$. Electrochim. Acta 2013, 113, 424-432.

(22) Cheng, F.; Xin, Y.; Chen, J.; Lu, L.; Zhang, X.; Zhou, H. Monodisperse $\mathrm{Li}_{1.2} \mathrm{Mn}_{0.6} \mathrm{Ni}_{0.2} \mathrm{O}_{2}$ microspheres with enhanced lithium storage capability. J. Mater. Chem. A 2013, 1, 5301-5308.

(23) Shen, C. H.; Wang, Q.; Fu, F.; Huang, L.; Lin, Z.; Shen, S. Y.; Su, H.; Zheng, X. M.; Xu, B. B.; Li, J. T.; Sun, S. G. Facile synthesis of the Li-rich layered oxide $\mathrm{Li}_{1.23} \mathrm{Ni}_{0.09} \mathrm{Co}_{0.12} \mathrm{Mn}_{0.56} \mathrm{O}_{2}$ with superior lithium storage performance and new insights into structural transformation of the layered oxide material during . ACS Appl. Mater. Interfaces 2014, 6, 5516-5524. 
(24) Li, J.; Zhan, C.; Lu, J.; Yuan, Y.; Shahbazian-Yassar, R.; Qiu, X.; Amine, K. Improve First-Cycle Efficiency and Rate Performance of Layered-Layered $\mathrm{Li}_{1.2} \mathrm{Mn}_{0.6} \mathrm{Ni}_{0.2} \mathrm{O}_{2} \mathrm{Us}_{\text {- }}$ ing Oxygen Stabilizing Dopant. ACS Appl. Mater. Interfaces 2015, 7, 16040-16045.

(25) Wang, Z.; Wu, M.; Xu, B.; Ouyang, C. Improving the electrical conductivity and structural stability of the $\mathrm{Li}_{2} \mathrm{MnO}_{3}$ cathode via P doping. J. Alloys Compd. 2016, 658, $818-823$.

(26) Gao, Y.; Ma, J.; Wang, X.; Lu, X.; Bai, Y.; Wang, Z.; Chen, L. Improved electron/Liion transport and oxygen stability of Mo-doped $\mathrm{Li}_{2} \mathrm{MnO}_{3}$. J. Mater. Chem. A 2014, 2, 4811.

(27) Yi, T. F.; Li, Y. M.; Yang, S. Y.; Zhu, Y. R.; Xie, Y. Improved Cycling Stability and Fast Charge-Discharge Performance of Cobalt-Free Lithium-Rich Oxides by MagnesiumDoping. ACS Appl. Mater. Interfaces 2016, 8, 32349-32359.

(28) Yu, R.; Wang, X.; Fu, Y.; Wang, L.; Cai, S.; Liu, M.; Lu, B.; Wang, G.; Wang, D.; Ren, Q.; Yang, X. Effect of magnesium doping on properties of lithium-rich layered oxide cathodes based on a one-step co-precipitation strategy. J. Mater. Chem. A 2016 , 4, 4941-4951.

(29) Hoang, K. Doping Li-rich cathode material $\mathrm{Li}_{2} \mathrm{MnO}_{3}$ : Interplay between lattice site preference, electronic structure, and delithiation mechanism. Phys. Rev. Mater. 2017, $075404,1-10$.

(30) Xiang, Y.; Wu, X. Enhanced electrochemical performances of $\mathrm{Li}_{2} \mathrm{MnO}_{3}$ cathode materials by $\mathrm{Al}$ doping. Ionics 2018, 24, 83-89.

(31) Blazquez-Alcover, I.; Rousse, G.; Alves Dalla Corte, D.; Badot, J. C.; Grimaud, A.; Rozier, P.; Tarascon, J. M. Improving ionic conductivity by Mg-doping of $\mathrm{A}_{2} \mathrm{SnO}_{3}(\mathrm{~A}$ $\left.=\mathrm{Li}^{+}, \mathrm{Na}^{+}\right)$. Solid State Ionics 2017, 308, 16-21. 
(32) Gao, Y.; Wang, X.; Ma, J.; Wang, Z.; Chen, L. Selecting substituent elements for Lirich Mn-based cathode materials by Density Functional Theory (DFT) calculations. Chem. Mater. 2015, 27, 3456-3461.

(33) Kong, F.; Longo, R. C.; Yeon, D. H.; Yoon, J.; Park, J. H.; Liang, C.; Kc, S.; Zheng, Y.; Doo, S. G.; Cho, K. Multivalent Li-Site Doping of Mn Oxides for Li-Ion Batteries. J. Phys. Chem. C 2015, 119, 21904-21912.

(34) Yan, P.; Zheng, J.; Zhang, X.; Xu, R.; Amine, K.; Xiao, J.; Zhang, J.-G.; Wang, C.-M. Atomic to Nanoscale Investigation of Functionalities of an $\mathrm{Al}_{2} \mathrm{O}_{3}$ Coating Layer on a Cathode for Enhanced Battery Performance. Chem. Mater. 2016, 28, 857-863.

(35) Liu, Y.; Wang, Q.; Zhang, Z.; Dou, A.; Pan, J.; Su, M. Investigation the electrochemical performance of layered cathode material $\mathrm{Li}_{1.2} \mathrm{Mn}_{0.6} \mathrm{Ni}_{0.2} \mathrm{O}_{2}$ coated with $\mathrm{Li}_{4} \mathrm{Ti}_{5} \mathrm{O}_{12}$. Adv. Powder Technol. 2016, 27, 1481-1487.

(36) Kim, S.; Cho, W.; Zhang, X.; Oshima, Y.; Choi, J. W. A stable lithium-rich surface structure for lithium-rich layered cathode materials. Nat. Commun. 2016, 7, 13598.

(37) Blomgren, G. E. The Development and Future of Lithium Ion Batteries. J. Electrochem. Soc. 2017, 164, A5019-A5025.

(38) Yu, D. Y. W.; Yanagida, K.; Kato, Y.; Nakamura, H. Electrochemical Activities in $\mathrm{Li}_{2} \mathrm{MnO}_{3}$. J. Electrochem. Soc. 2009, 156, A417.

(39) Boulineau, A.; Croguennec, L.; Delmas, C.; Weill, F. Structure of $\mathrm{Li}_{2} \mathrm{MnO}_{3}$ with different degrees of defects. Solid State Ionics 2010, 180, 1652-1659.

(40) Boulineau, A.; Croguennec, L.; Delmas, C.; Weill, F. Reinvestigation of $\mathrm{Li}_{2} \mathrm{MnO}_{3}$ structure: Electron diffraction and high resolution TEM. Chem. Mater. 2009, 21, 4216-4222.

(41) Lei, C. H.; Wen, J. G.; Sardela, M.; Bareño, J.; Petrov, I.; Kang, S. H.; Abraham, D. P. 
Structural study of $\mathrm{Li}_{2} \mathrm{MnO}_{3}$ by electron microscopy. J. Mater. Sci. 2009, 44, 55795587.

(42) Serrano-Sevillano, J.; Reynaud, M.; Saracibar, A.; Altantzis, T.; Bals, S.; van Tendeloo, G.; Casas-Cabanas, M. Enhanced electrochemical performance of Li-rich cathode materials through microstructural control. Phys. Chem. Chem. Phys. 2018, 20, 2311223122.

(43) Matsunaga, T.; Komatsu, H.; Shimoda, K.; Minato, T.; Yonemura, M.; Kamiyama, T.; Kobayashi, S.; Kato, T.; Hirayama, T.; Ikuhara, Y.; Arai, H.; Ukyo, Y.; Uchimoto, Y.; Ogumi, Z. Dependence of Structural Defects in $\mathrm{Li}_{2} \mathrm{MnO}_{3}$ on Synthesis Temperature. Chem. Mater. 2016, 28, 4143-4150.

(44) Bréger, J.; Jiang, M.; Dupré, N.; Meng, Y. S.; Shao-Horn, Y.; Ceder, G.; Grey, C. P. High-resolution X-ray diffraction, DIFFaX, NMR and first principles study of disorder in the $\mathrm{Li}_{2} \mathrm{MnO}_{3}-\mathrm{Li}\left[\mathrm{Ni}_{1 / 2} \mathrm{Mn}_{1 / 2}\right] \mathrm{O}_{2}$ solid solution. J. Solid State Chem. 2005, 178, 25752585 .

(45) Seymour, I. D.; Middlemiss, D. S.; Halat, D. M.; Trease, N. M.; Pell, A. J.; Grey, C. P. Characterizing Oxygen Local Environments in Paramagnetic Battery Materials via ${ }^{17} \mathrm{O}$ NMR and DFT Calculations. J. Am. Chem. Soc. 2016, 138, 9405-9408.

(46) Treacy, M. M.; Newsam, J. M.; Deem, M. W. A general recursion method for calculating diffracted intensities from crystals containing planar faults. Proc. R. Soc. Lond. Ser. A 1991, 433, 499-520.

(47) Casas-Cabanas, M.; Rodríguez-Carvajal, J.; Palacín, M. R. Faults, a New Program for Refinement of Powder Diffraction Patterns From Layered Structures. Z. Kristallogr. 2006, 23, 243-248.

(48) Casas-Cabanas, M.; Reynaud, M.; Rikarte-Ormazabal, J.; Horbach, P.; Rodríguez- 
Carvajal, J. FAULTS. Available as a Sub-Program of the FullProf Suite. 2015, FAULTS. Available as a sub-program of the FullProf.

(49) Casas-Cabanas, M.; Reynaud, M.; Rikarte, J.; Horbach, P.; Rodríguez-Carvajal, J. FAULTS: A program for refinement of structures with extended defects. J. Appl. Crystallogr. 2016, 49, 2259-2269.

(50) Casas-Cabanas, M.; Rodríguez-Carvajal, J.; Canales-Vázquez, J.; Laligant, Y.; Lacorre, P.; Palacín, M. R. Microstructural characterisation of battery materials using powder diffraction data: DIFFaX, FAULTS and SH-FullProf approaches. J. Power Sources 2007, 174, 414-420.

(51) Reynaud, M.; Casas-Cabanas, M. Order and disorder in NMC layered materials: A FAULTS simulation analysis. Powder Diffr. 2017, 32, S213-S220.

(52) Liu, J.; Yin, L.; Wu, L.; Bai, J.; Bak, S. M.; Yu, X.; Zhu, Y.; Yang, X. Q.; Khalifah, P. G. Quantification of Honeycomb Number-Type Stacking Faults: Application to $\mathrm{Na}_{3} \mathrm{Ni}_{2} \mathrm{BiO}_{6}$ Cathodes for Na-Ion Batteries. Inorg. Chem. 2016, 55, 8478-8492.

(53) Shunmugasundaram, R.; Arumugam, R. S.; Dahn, J. R. A Study of Stacking Faults and Superlattice Ordering in Some Li-Rich Layered Transition Metal Oxide Positive Electrode Materials. J. Electrochem. Soc. 2016, 163, A1394-A1400.

(54) Biscoe, J.; Warren, B. E. An x-ray study of carbon black. J. Appl. Phys. 1942, 13, $364-371$.

(55) Grey, C. P.; Lee, Y. J. Lithium MAS NMR studies of cathode materials for lithium-ion batteries. Solid State Sci. 2003, 5, 883-894.

(56) Delmas, C.; Carlier, D.; Ceder, G.; Ménétrier, M.; Grey, C. P. Understanding the NMR shifts in paramagnetic transition metal oxides using density functional theory calculations. Phys. Rev. B: Condens. Matter Mater. Phys. 2003, 67, 174103. 
(57) Zhang, Y.; Castets, A.; Carlier, D.; Ménétrier, M.; Boucher, F. Simulation of NMR Fermi contact shifts for lithium battery materials: The need for an efficient hybrid functional approach. J. Phys. Chem. C 2012, 116, 17393-17402.

(58) Castets, A.; Carlier, D.; Zhang, Y.; Boucher, F.; Ménétrier, M. A DFT-based analysis of the NMR fermi contact shifts in tavorite-like $\mathrm{LiMPO}_{4} \cdot \mathrm{OH}$ and $\mathrm{MPO}_{4} \cdot \mathrm{H}_{2} \mathrm{O}(\mathrm{M}=\mathrm{Fe}$, Mn, V). J. Phys. Chem. C 2012, 116, 18002-18014.

(59) Bamine, T.; Boivin, E.; Boucher, F.; Messinger, R. J.; Salager, E.; Deschamps, M.; Masquelier, C.; Croguennec, L.; Ménétrier, M.; Carlier, D. Understanding Local Defects in Li-Ion Battery Electrodes through Combined DFT/NMR Studies: Application to LiVPO $_{4}$ F. J. Phys. Chem. C 2017, 121, 3219-3227.

(60) Morgan, K. R.; Collier, S.; Burns, G.; Ooi, K. A ${ }^{6} \mathrm{Li}$ and ${ }^{7} \mathrm{Li}$ MAS NMR study of the spinel-type manganese oxide $\operatorname{LiMn}_{2} \mathrm{O}_{4}$ and the rock salt-type manganese oxide $\mathrm{Li}_{2} \mathrm{MnO}_{3}$. J. Chem. Soc., Chem. Commun. 1994, 2, 1719-1720.

(61) Mustarelli, P.; Massarotti, V.; Bini, M.; Capsoni, D. Transferred hyperfine interaction and structure in $\mathrm{LiMn}_{2} \mathrm{O}_{4}$ and $\mathrm{Li}_{2} \mathrm{MnO}_{3}$ coexisting phases: A XRD and ${ }^{7} \mathrm{Li}$ NMR-MAS study. Phys. Rev. B 1997, 55, 12018-12024.

(62) Lee, Y. J.; Wang, F.; Grey, C. P. ${ }^{6} \mathrm{Li}$ and ${ }^{7} \mathrm{Li}$ MAS NMR studies of lithium manganate cathode materials. J. Am. Chem. Soc. 1998, 120, 12601-12613.

(63) Lee, Y. J.; Grey, C. P. Determining the lithium local environments in the lithium manganates $\mathrm{LiZn}_{0.5} \mathrm{Mn}_{1.5} \mathrm{O}_{4}$ and $\mathrm{Li}_{2} \mathrm{MnO}_{3}$ by analysis of the ${ }^{6} \mathrm{Li}$ MAS NMR spinning sideband manifolds. J. Phys. Chem. B 2002, 106, 3576-3582.

(64) Pecher, O.; Halat, D. M.; Lee, J.; Liu, Z.; Griffith, K. J.; Braun, M.; Grey, C. P. Enhanced efficiency of solid-state NMR investigations of energy materials using an external automatic tuning/matching (eATM) robot. J. Magn. Reson. 2017, 275, 127136. 
(65) Bertini, I.; Luchinat, C.; Parigi, G. Magnetic susceptibility in paramagnetic NMR. Prog. Nucl. Magn. Reson. Spectrosc. 2002, 40, 249-273.

(66) Ong, S. P.; Richards, W. D.; Jain, A.; Hautier, G.; Kocher, M.; Cholia, S.; Gunter, D.; Chevrier, V. L.; Persson, K. A.; Ceder, G. Python Materials Genomics (pymatgen): A robust, open-source python library for materials analysis. Comput. Mater. Sci. 2013, $68,314-319$.

(67) Tang, W.; Kanoh, H.; Yang, X.; Ooi, K. Preparation of plate-form manganese oxide by selective lithium extraction from monoclinic $\mathrm{Li}_{2} \mathrm{MnO}_{3}$ under hydrothermal conditions. Chem. Mater. 2000, 12, 3271-3279.

(68) Robertson, A. D.; Bruce, P. G. Mechanism of electrochemical activity in $\mathrm{Li}_{2} \mathrm{MnO}_{3}$. Chem. Mater. 2003, 15, 1984-1992.

(69) Armstrong, A.; Robertson, A.; Bruce, P. Overcharging manganese oxides: Extracting lithium beyond $\mathrm{Mn}^{4+}$. J. Power Sources 2005, 146, 275-280.

(70) Benedek, R.; Thackeray, M. M.; van de Walle, A. Free Energy for Protonation Reaction in Lithium-Ion Battery Cathode Materials. Chem. Mater. 2008, 20, 5485-5490.

(71) Rana, J.; Stan, M.; Kloepsch, R.; Li, J.; Schumacher, G.; Welter, E.; Zizak, I.; Banhart, J.; Winter, M. Structural Changes in $\mathrm{Li}_{2} \mathrm{MnO}_{3}$ Cathode Material for Li-Ion Batteries. Adv. Energy Mater. 2014, 4, 1300998.

(72) Delmas, C. Battery materials: Operating through oxygen. Nat. Chem. 2016, 8, 641643.

(73) Seo, D. H.; Lee, J.; Urban, A.; Malik, R.; Kang, S.; Ceder, G. The structural and chemical origin of the oxygen redox activity in layered and cation-disordered Li-excess cathode materials. Nat. Chem. 2016, 8, 692-697. 
(74) Luo, K.; Roberts, M. R.; Hao, R.; Guerrini, N.; Pickup, D. M.; Liu, Y. S.; Edström, K.; Guo, J.; Chadwick, A. V.; Duda, L. C.; Bruce, P. G. Charge-compensation in 3dtransition-metal-oxide intercalation cathodes through the generation of localized electron holes on oxygen. Nat. Chem. 2016, 8, 684-691.

(75) Xiao, R.; Li, H.; Chen, L. Density functional investigation on $\mathrm{Li}_{2} \mathrm{MnO}_{3}$. Chem. Mater. 2012, 24, 4242-4251.

(76) Kubota, K.; Kaneko, T.; Hirayama, M.; Yonemura, M.; Imanari, Y.; Nakane, K.; Kanno, R. Direct synthesis of oxygen-deficient $\mathrm{Li}_{2} \mathrm{MnO}_{3-x}$ for high capacity lithium battery electrodes. J. Power Sources 2012, 216, 249-255.

(77) Tan, X.; Liu, R.; Xie, C.; Shen, Q. Modified structural characteristics and enhanced electrochemical properties of oxygen-deficient $\mathrm{Li}_{2} \mathrm{MnO}_{3-\Delta}$ obtained from pristine $\mathrm{Li}_{2} \mathrm{MnO}_{3}$. J. Power Sources 2018, 374, 134-141.

(78) James, C.; Wu, Y.; Sheldon, B. W.; Qi, Y. The impact of oxygen vacancies on lithium vacancy formation and diffusion in $\mathrm{Li}_{2-x} \mathrm{MnO}_{3-\delta}$. Solid State Ionics 2016, 289, 87-94.

(79) Jacob, C.; Jian, J.; Su, Q.; Verkhoturov, S.; Guillemette, R.; Wang, H. Electrochemical and structural effects of in situ $\mathrm{Li}_{2} \mathrm{O}$ extraction from $\mathrm{Li}_{2} \mathrm{MnO}_{3}$ for li-ion batteries. ACS Appl. Mater. Interfaces 2015, 7, 2433-2438.

(80) Johnson, C. S.; Kim, J. S.; Lefief, C.; Li, N.; Vaughey, J. T.; Thackeray, M. M. The significance of the $\mathrm{Li}_{2} \mathrm{MnO}_{3}$ component in 'composite' $\mathrm{xLi}_{2} \mathrm{MnO}_{3} \cdot(1-\mathrm{x}) \mathrm{LiMn}_{0.5} \mathrm{Ni}_{0.5} \mathrm{O}_{2}$ electrodes. Electrochem. Commun. 2004, 6, 1085-1091.

(81) Francis Amalraj, S.; Markovsky, B.; Sharon, D.; Talianker, M.; Zinigrad, E.; Persky, R.; Haik, O.; Grinblat, J.; Lampert, J.; Schulz-Dobrick, M.; Garsuch, A.; Burlaka, L.; Aurbach, D. Study of the electrochemical behavior of the "inactive" $\mathrm{Li}_{2} \mathrm{MnO}_{3}$. Electrochim. Acta 2012, 78, 32-39. 
(82) Neudecker, B.; Zuhr, R.; Kwak, B.; Bates, J. Lithium Manganese Nickel Oxides $\mathrm{Li}_{x}\left(\mathrm{Mn}_{y} \mathrm{Ni}_{1-y}\right)_{2-x} \mathrm{O}_{2}$. J. Electrochem. Soc. 1998, 145, 4148-4159.

(83) Thackeray, M. M.; Johnson, C. S.; Vaughey, J. T.; Li, N.; Hackney, S. A. Advances in manganese-oxide 'composite' electrodes for lithium-ion batteries. J. Mater. Chem. 2005, 15, 2257-2267.

(84) Rossouw, M.; Thackeray, M. Lithium manganese oxides from $\mathrm{Li}_{2} \mathrm{MnO}_{3}$ for rechargeable lithium battery applications. Mater. Res. Bull. 1991, 26, 463-473.

(85) Kang, S.-H.; Johnson, C. S.; Vaughey, J. T.; Amine, K.; Thackeray, M. M. The Effects of Acid Treatment on the Electrochemical Properties of $0.5 \mathrm{Li}_{2} \mathrm{MnO}_{3} \cdot 0.5 \mathrm{LiNi}_{0.44} \mathrm{Co}_{0.25} \mathrm{Mn}_{0.31} \mathrm{O}_{2}$ Electrodes in Lithium Cells. J. Electrochem. Soc. 2006, 153, A1186.

(86) Okamoto, Y. Ambivalent Effect of Oxygen Vacancies on $\mathrm{Li}_{2} \mathrm{MnO}_{3}$ : A First-Principles Study. J. Electrochem. Soc. 2011, 159, A152-A157.

(87) Hoang, K. Defect physics, delithiation mechanism, and electronic and ionic conduction in layered lithium manganese oxide cathode materials. Phys. Rev. Appl. 2015, 3, 1-17.

(88) Longo, R. C.; Kong, F. T.; Santosh, K. C.; Park, M. S.; Yoon, J.; Yeon, D. H.; Park, J. H.; Doo, S. G.; Cho, K. Phase stability of Li-Mn-O oxides as cathode materials for Li-ion batteries: Insights from ab initio calculations. Phys. Chem. Chem. Phys. 2014, 16, 11233-11242.

(89) Momma, K.; Izumi, F. VESTA: A three-dimensional visualization system for electronic and structural analysis. J. Appl. Crystallogr. 2008, 41, 653-658.

(90) Momma, K.; Izumi, F. VESTA 3 for three-dimensional visualization of crystal, volumetric and morphology data. J. Appl. Crystallogr. 2011, 44, 1272-1276.

(91) Momma, K.; Izumi, F. VESTA Manual. 2014, 1-2. 
(92) Massiot, D.; Fayon, F.; Capron, M.; King, I.; Le Calvé, S.; Alonso, B.; Durand, J. O.; Bujoli, B.; Gan, Z.; Hoatson, G. Modelling one- and two-dimensional solid-state NMR spectra. Magn. Reson. Chem. 2002, 40, 70-76.

(93) Kresse, G.; Furthmüller, J. Efficiency of ab-initio total energy calculations for metals and semiconductors using a plane-wave basis set. Comput. Mater. Sci. 1996, 6, 15-50.

(94) Joubert, D. From ultrasoft pseudopotentials to the projector augmented-wave method. Phys. Rev. B: Condens. Matter Mater. Phys. 1999, 59, 1758-1775.

(95) Blaha, P.; Schwarz, K.; Madsen, G. K. H.; Kvasnicka, D.; Luitz, J. WIEN2k, An Augmented Plane Wave + Local Orbitals Program for Calculating Crystal Properties. Technische Universität Wien, Austria 2001,

(96) Perdew, J. P.; Burke, K.; Ernzerhof, M. Generalized gradient approximation made simple. Phys. Rev. Lett. 1996, r7, 3865-3868.

(97) Dudarev, S. L.; Botton, G. A.; Savrasov, S. Y.; Szotek, Z.; Temmerman, W. M.; Sutton, A. P. Electronic structure and elastic properties of strongly correlated metal oxides from first principles: LSDA + U, SIC-LSDA and EELS study of $\mathrm{UO}_{2}$ and NiO. Phys. Status Solidi A 1998, 166, 429-443. 


\section{Graphical TOC Entry}

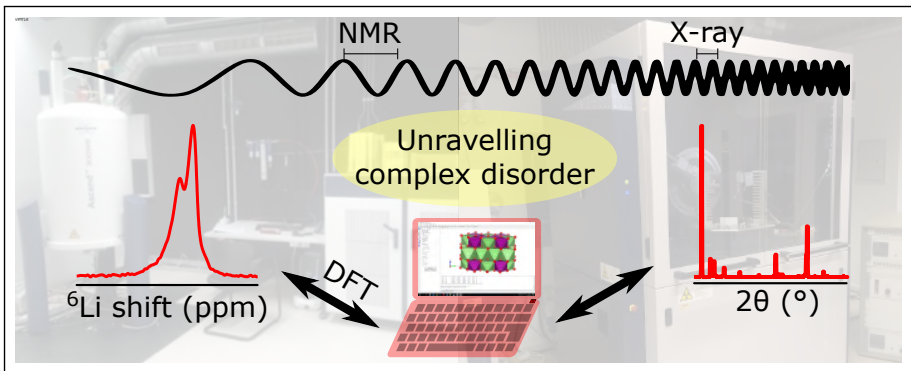

In this work how an in-depth combination of XRD and solid-state NMR analyses can provide a very accurate qualitative and quantitative description of the defects present in $\mathrm{Li}_{2} \mathrm{MnO}_{3}$ is shown, ranging from the atomistic point of view of NMR and DFT to the long-range structural characterization of XRD supported by the FAULTS diffraction refinement program. 